\title{
Esferas (ocultas) de participação política dos jovens na cidade da Praia, Cabo Verde: do político ao parapolítico
}

\author{
(Hidden) Spheres of youth political participation in the city of Praia, \\ Cape Verde: from political to parapolitics
}

\section{Aquilino Varela Redy Wilson Lima}

\section{Resumo}

Trabalhar esferas de participação política dos jovens na Praia, capital de Cabo Verde, constitui o objetivo deste artigo. Partindo de uma análise qualitativa e quantitativa, mapeamos as instâncias reservadas à participação política juvenil e exumamos a trajetória emergente forjada pelos jovens no sentido de expressarem o seu relacionamento com as instituiçóes políticas, sobretudo o Governo e os Partidos Políticos. Esferas mercantilistas e parapolíticas expressas em grupos de rap e gangues de rua constituem novas tendências organizacionais e participacionistas dos jovens praienses que, num contexto marcado por desigualdades e dificuldades de acesso às oportunidades sociais, encontram no mercado eleitoral possibilidades de afirmação social.

\section{Palavras-chave}

Gangues de Rua; Rap; Participação Política Juvenil; Partidos Políticos; Cabo Verde.

\begin{abstract}
This article seeks to study the spheres of youth political participation in Praia, capital city of Cape Verde. From a qualitative and quantitative analysis, we map the levels reserved to youth political participation and we disclose the emerging trajectory forged by youths in order to express their relationship with political institutions, especially the Government and Political Parties. Mercantilist and parapolitical spheres conveyed by some rap groups and street gangs represent new organizational and participative trends of Praia youth who, in a context marked by inequalities and difficulties in the access to social opportunities, find in the electoral market possibilities of social affirmation.
\end{abstract}

\section{Keywords}

Street Gangs; Rap; Youth Political Participation; Political Parties; Cape Verde. 


\section{Introdução}

Busca-se, com este trabalho, aportar o debate sobre as esferas participativas dos jovens em Cabo Verde, seu significado e a sua repercussão no sistema democrático.

Participação política enquanto atividade voluntária pela qual os membros de uma sociedade procedem à seleção dos governantes e à formação da opinião pública (McCLOSKY, 1968) é uma das dimensões do sistema poliárquico (DAHL, 1971) e constitui variável dependente que a Ciência Política procura recuperar na análise do sistema democrático.

A literatura especializada (ALMOND e VERBA, 1963; PATEMAN, 1992; PUTNAM, 1996; INGLEHART e WELZEL, 2009; GONZALEZ e CASTRO, 2008; MOISÉS, 2010; BAQUERO, 2001) demonstra que, regra geral, a participação varia com o sistema político e com a cultura política. Ou seja, possibilidades objetivas e vontades subjetivas constituem caldos possíveis da sua promoção. Contudo, ao agendar o debate, neste trabalho, a intenção é ampliar o interesse da comunidade científica e a percepção dos agentes públicos sobre os seus efeitos das participaçóes juvenis emergentes sobre as instituições políticas.

Esquematiza-se o presente artigo em três objetivos: (1) mapear contextos de participação política proporcionados pelo regime de Partido-único e pela Democracia; (2) debater a avaliação da percepção de participação política por parte de agências oficiais; (3) trazer para a reflexão alguns mercados, como gangues de rua e rappers, que estruturam a participaçáo juvenil na atualidade.

\section{Contextos de participação politica em Cabo Verde: interfaces entre Sociedade e o Estado}

Intentar-se-á, neste ponto, desenvolver a premissa de que em Cabo Verde, desde o período tardo colonial, passando pela Primeira República (1975-1990), o(s) Estado(s) institucionalizado(s) de forma autocentrada bloquearam a liberdade, o pluralismo e, concomitantemente, congelaram a participação política, gerando padróes residuais de participação com altos custos de reversão. Todavia, ao nível da juventude, não obstante a democracia conquistada em 1991 consagrar amplas esferas de participação, para tolher aquele feedback positivo, o poder político vem conviver com práticas de participação parapolíticas, náo negligenciáveis e não sem contestações. 
Até um passado recente, a Constituição da República (1980) consagrava o PAIGC 1 , partido-único, como força dirigente da sociedade e do Estado, com poderes exclusivos para escolher titulares dos órgáos do poder, criar, autorizar e gerir as organizaçóes sociais. Como se vê, a cidadania plena foi restringida aos afetos do partido. A sociabilidade e a participação dos indivíduos na res pública foram, também, reduzidas ao seu escopo. Desta forma, a participação na perspectiva de "ter o direito de ter direitos" (ARENDT, 1998) não era acessível a todos. A cidadania enquanto capacidade de participar do poder político de forma generalizada e organizada, em Cabo Verde, esteve associada à revogação dos privilégios autoconsagrados das "elites do poder" (MILLS, 1962) que vieram da luta de libertação. Foi só com o advento da democratização que a participação cidadã foi instaurada.

Contudo, a Primeira República permitia exceçóes. Recorda-se que o sistema político de então criou organizaçóes que servissem de seu "tentáculo" e garantissem a reprodutibilidade do seu ethos. São exemplos: a Organização dos Pioneiros Abel Djassi de Cabo Verde - OPAD-CV; Juventude Africana Amílcar Cabral de Cabo Verde - JAAC-CV; e a Organização das Mulheres de Cabo Verde - OMCV.

Ademais, registra-se que o espaço social não era o único cuja posse o Estado colonial e nacional da Primeira República mantinha o controle. O âmbito econômico também esteve subjugado ao poder estatal. De um Estado extrativista colonial passouse a um Estado planejador e totalitário. Como afirma Querido (2011),

O artigo quarto da Constituição de 1980, decalcado inteiramente do artigo sexto da Constituição da Uniấo Soviética, veio a dar o golpe final nas esperanças daqueles que aceitaram e aplaudiram a tomada de poder pelo PAIGC, em 1975, em regime de exclusivo, convencidos de que, passada a fase crítica, o poder seria naturalmente retornado ao seu único e verdadeiro depositário: o povo (p. 222).

Esta Constituição definia como propriedades do Estado o setor econômico, meios básicos de produção industrial, informação, comunicação, bancos, seguros e os meios de transporte. Nestes termos, ao atentar na ordem clássica de caracterização da cidadania no Reino Unido de Marshall (1967) que distingue uma sequência de três aspectos - civil, político e socioeconômico - poder-se-ia afirmar que em Cabo Verde, contrariamente aquela região do mundo, a cidadania social pré-existiu à cidadania política. Diferenciação que, de resto, Murilo de Carvalho (2002) propõe também

\footnotetext{
${ }^{1}$ Partido Africano da Independência da Guiné e de Cabo Verde.
} 
para o Brasil no contexto de desenvolvimento de Vargas. Seja como for, a explicação pode ser encontrada na natureza do estado autoritário e assistencialista edificado pelo PAIGC/CV num contexto de tamanha vulnerabilidade social ${ }^{2}$ da independência.

A inversão-torção deste status quo se iniciou com as primeiras eleições livres e democráticas que instaurou uma democracia com os requisitos da poliarquia (DAHL, 1971). Cabo Verde, de lá para cá, cresce a sua pontuação em termos da classificação democrática proposta pela Freedom House (2013). Atualmente o país é tido como inteiramente Free com uma classificação de 1 (um) para Direitos Políticos e 1 (um) para as Liberdades Civis. Porém, a democracia não é uma varinha mágica que induz o desenvolvimento. O país confronta-se com uma acelerada contração dos direitos sociais e econômicos, em virtude da pressão populacional ${ }^{3}$ sobre os recursos, perante uma economia dependente de fontes exógenas de financiamento como Ajudas Públicas ao Desenvolvimento (APD), remessas dos emigrantes e turismo. Recursos não que dependem das flutuaçóes na conjuntura internacional. Pressupostos que talvez expliquem o porquê que a democracia conquistada em Cabo Verde, decorridos poucos anos, apenas difusamente tem encontrado respaldo no social.

É nosso entendimento que no contexto da democratização do país faz todo o sentido resgatar o Estado como variável independente que afeta a estrutura de relações sociais e intervém na elaboração e implementação de políticas públicas em interação com a sociedade. Ao se aperceber os redimensionamentos das instituições políticas com enfoque no Estado, talvez se compreenda melhor tanto os obstáculos que dificultam a consolidação da democracia nas ilhas como os aspectos que the vem infestando. $\mathrm{O}$ argumento, sintetizamos, foi a edificação de um Estado dependente e punitivo, com o seu cortejo de restriçóes: a adoção de uma cultura de controle, a construção de uma entidade política plenipotenciária e a contração de espaços livres de direito (suportada em reais corporificaçóes, ou estribada em ideologias totalitárias). As relações de osmose entre instituições políticas/sociedade são importantes para o processo da democracia, e difíceis de harmonizar, mormente em um país neófito e

\footnotetext{
2 Várias foram as secas e as fomes que ensombraram a história de Cabo Verde. As últimas foram na década de quarenta do século XX que dizimaram mais da metade da população. Especialmente, a de 1947 é lembrada como a pior de que se tem a memória em Cabo Verde. A obra Famintos (1962) do escritor cabo-verdiano Luís Romano, falecido recentemente em Brasil onde residia, dá um panorama geral desse fenômeno, cujo espectro ainda se encontra presente no seio da populaçáo.

${ }^{3}$ Nos últimos trinta anos a população cabo-verdiana duplicou de duzentos e cinquenta e três mil na época da independência para aproximadamente $500 \mathrm{mil}$, com uma taxa de dependência juvenil de $51 \%$ e um desemprego de $27,1 \%$ (INE, 2010).
} 
vulnerável como Cabo Verde que conta ainda com escassas três e duas décadas, respectivamente, da sua independência e democracia política. A questão é como conciliar esse pano de fundo com a democracia representativa existente.

Com um repertório de cinco eleições legislativas no contexto de uma democracia parlamentar, conquistada a partir da denominada "terceira onda democrática", (HUNTINGTON, 1991), Cabo Verde vem estruturar as suas instituições de forma suis generis no espaço africano. Do ponto de vista dos partidos políticos, explorados neste artigo, apesar da sua precária institucionalização, eles mantêm bases eleitorais consideravelmente estáveis. A nosso ver, essas bases de apoio, como à frente demonstraremos, tendo como pano de fundo a análise de três períodos eleitorais - autárquicas de 2008 e 2012, legislativas e presidenciais de 2011, na Cidade da Praia - resultam de práticas escamoteadas na competição política por alguns agentes.

Portanto, observando os partidos políticos na sociedade e o seu pleno preenchimento na arena estatal, com o monopólio do spoilsystem (WEBER, 2004), o eleitorado escolhe de forma racional e fornece o seu apoio ao sistema partidário, calculando o retorno a obter com o seu voto de acordo com esquemas individuais e não coletivos. Assim, o apoio eleitoral que os cidadãos dão aos partidos políticos neste país, na nossa perspectiva, afere mais dos resultados dessas ponderaçôes do que propriamente do grau de institucionalização de sistemas partidários (VARELA, 2014). Anthony Downs (1999) registrou que

os partidos políticos, numa democracia, planejam suas políticas de modo a maximizar votos. Em contrapartida, todo o cidadão tenta racionalmente a maximizar sua renda de utilidade, inclusive aquela parcela que deriva da atividade governamental (DOWNS, 1999, p. 31).

Para este autor, "os partidos na política democrática são análogos aos empresários numa economia que busque o lucro. De modo a atingir os seus fins privados, eles formulam as políticas que acreditam que lhes trarão mais votos" (DOWNS, 1999, p. 313). A um outro nível, que não do eleitorado, mas dos aderentes partidários, os líderes partidários, como sugere Panebianco (2005), têm que pleitear os recursos de remuneração política de forma a poder distribuir incentivos coletivos - identidade partilhada; e incentivos seletivos - recompensas materiais aos filiados.

Nestes termos, quando Sanches (2013) afirma que em Cabo Verde 
a democratização e institucionalização parecem caminhar lado a lado. Com efeito, para além de partidos estáveis, que se vão alternando ocasionalmente no poder, que definem padrôes estáveis de interação, criam simpatias duráveis entre os cidadãos e têm identidades organizacionais firmes ao longo do tempo, encontramos partidos comprometidos com as tarefas de democratização (SANCHES, 2013, p. 267).

É no mínimo ou um exercício acrítico de importação de teorias já elaboradas (LAMOUNIER, 1987 e 1990; MAINWARING e SCULLY, 1995; KINZO, 2005) sem que se examine ou etnografe a realidade, ou uma aposta ortodoxa em ilustrar a realidade (sem a decompor) com a teoria.

\section{Transições politicas em Cabo Verde: o novo e o velho lugar da participação juvenil}

Em 2008, o jornal $A$ Naçáo noticiou que o registro de eleitores jovens para as eleiçóes que se avizinhavam tinha ficado aquém do esperado, realçando o seu desinteresse político, fato confirmado por Évora e Ramos (2013). Imagem, no entanto, ultrapassada nas posteriores campanhas partidárias devido à forte mobilização de militantes partidários jovens de todos os estratos sociais.

Braga da Cruz (1985) explica que pode dar-se o caso de uma forte mobilização se confrontar com a ausência de interesse, gerando então uma situação de indiferença, condição, por sua vez, de alienação. Confrontando os termos politização e despolitização, o autor refere que, no uso corrente, o primeiro diz respeito às instituições e o segundo à atividade do homem. Isto é, ao se falar de politização das instituições, subentende-se a sua excessiva partidarização ou ideologização e, ao se falar de despolitização, está-se a mencionar a diminuição do interesse pela política ou da consciência política, ou ainda o decréscimo da participação.

No contexto em apreço, a independência para fortalecer os laços de identidade nacional procedeu com a politização das instituições, por um lado, e a alienação político-partidária de crianças e jovens como forma de instrumentalização ideológica (LIMA, 2012), por outro. A participação política juvenil, nesse contexto, tinha existência apenas no interior da esfera partidária, conseguindo desta feita anular dinâmicas juvenis que no período colonial fizeram emergir importantes manifestaçóes socioculturais e políticas.

Cardoso (1993) considerou que o fenômeno de castração cívica da população foi premeditado e visava destruir uma sociedade civil dinâmica, sobretudo a nível intelectual, transformando-a naquilo a que Costa (2013) chamou de sociedade servil. 
Em entrevista a José Vicente Lopes (2012), Aristides Pereira, ex-Presidente da República, lembra o incômodo que a expressão sociedade civil acarretava nos finais dos anos de 1980. Segundo testemunha, os jovens quadros do partido, do qual faziam parte alguns dos atuais dirigentes do país, eram os mais relutantes à mudança e a quem a expressão mais inquietava.

Antes, no contexto da luta armada, o fundador do PAIGC, Amílcar Cabral, chamara atenção em relação aos comportamentos oportunistas dos guerrilheiros do PAIGC que segundo as suas palavras, "estão a sacrificar-se muito, mas com a ideia de que amanhã vão gozar, com bom automóvel, criados, várias mulheres, etc" (CABRAL, 2013, p. 196). No período pós-independência, explicou Pereira (apud LOPES, 2012), notava-se que alguns dirigentes orientavam-se por uma ganância desmesurada e sede de poder.

Para Varela, a pequena elite burguesa produzida pela administração pública colonial que liderou a luta para a independência da Guiné-Bissau e de Cabo Verde ambicionava de tal forma o poder, que no período posterior à independência "continuaram a utilizar a estrutura oficial estatal para tentar manter outros grupos sociais à margem da partilha do poder” (VARELA, 2013, p. 190). Esta programação partidária levou a uma despolitização juvenil, alcançada pela anestesia social, que incute a nova consciência político-partidária. Considerando que este princípio fazia sentido no contexto da luta armada em que o inimigo era real, no contexto pós-luta armada entendemos-a como uma tentativa de controle para manutenção de poder e criação da personagem yesman (LIMA, 2012), que trai o discurso de Cabral sobre a juventude.

\footnotetext{
Nós não queremos criados, não queremos servidores, não queremos rapazes para mandar neles. Nós queremos homens, camaradas conscientes, camaradas nossos, capazes de levantar a cabeça diante de nós, de discutir com respeito, como deve ser. Queremos homens e mulheres conscientes, de cabeça levantada, e temos lutado duro contra a tendência de dirigentes ou de responsáveis de fazer os rapazinhos andar atrás deles, de fazer outros responsáveis que estão debaixo das suas ordens como se fossem os seus meninos de recado (CABRAL, 2013, p. 178-179).
}

A narrativa de segunda libertação popular dos anos de 1990 legitimada pelos "democratas" permitiu aos jovens a construção de um novo lugar de reivindicação e participação política. Logo após a abertura democrática, reagindo às políticas educativas do governo do Movimento Para a Democracia (MPD) pela primeira vez na história do país os estudantes do Ensino Secundário reagiram de forma organizada, 
paralisando as aulas e as ruas da cidade numa clara demonstração de força e interiorização das ideias de liberdade propalada pelos "democratas". O pico de maior violência aconteceu em 12 de Abril de 1994, em que se juntou aos protestos uma parte da população desalojada, de um dos bairros ditos espontâneos, pela Câmara Municipal da Praia.

Vinte e um feridos, três detenções, palácio do Governo e várias viaturas com vidros partidos e pilhados é o resultado dos distúrbios registrados na passada terça-feira, 12 - considerado dia negro para a cidade da Praia (NOVO JORNAL DE CABO VERDE, 1994, p. 11).

Jornais da praça - Novo Jornal de Cabo Verde e A Semana, tidos como consecutivamente afetos ao governo e à oposição - fizeram leituras opostas do acontecimento. Se de um lado, uma parte dos estudantes eram culpabilizados por terem participado nos distúrbios e não terem informado a polícia sobre as infiltrações de pessoas estranhas ao seu universo, de outro, eram protegidos e questionava-se a desproporcionalidade do uso da força pela polícia.

Resnick e Casale (2011) lembram que apesar de se colocar ênfase na ida às urnas, quando se aborda a questão da participação política convém ter em conta que ela manifesta-se de várias formas: tanto pode ser a partir do envolvimento em processos políticos formais quanto como protestos de rua. Muxel (1997) afirma que dependendo dos contextos históricos os diagnósticos da participação política juvenil poderão ser mais ou menos otimistas ou mais ou menos pessimistas. Da geração engajada e politizada dos anos de 1960, tal como foi a geração de Cabral, passamos a uma geração apática e despolitizada no decorrer dos anos de 1970, até os finais dos anos de 1980. A geração protagonista das manifestações dos anos de 1990 na Praia insere-se na fase realista e pragmática da juventude que segundo a autora, falando do caso francês, dominou o universo político juvenil daquela época. As mobilizações estudantis da Praia devem ser enquadradas nas estruturas de oportunidades políticas que os processos de democratizaçáo e mudança de regime possibilitaram (COSTA, 2013), assim como a sua existência efêmera e as razões que levaram à sua posterior despolitização (se é que estavam politizadas) na pós-manifestação estudantil de Abril de 1994 devem ser percebidas como consequência da excessiva institucionalização juvenil no Estado Pós-Colonial cabo-verdiano.

A abertura democrática, longe de despartidarizar os jovens, deu continuidade institucional contribuindo para a reprodução da dependência institucional juvenil e consolidação do sistema bipartidário. A letargia cívica e o declínio do ativismo político, neste período, são explicados por Costa (2013), dentre outros fatores, pela 
colonização consciente da sociedade civil por parte das estruturas governamentais e partidárias acopladas numa estratégia de cooptação através da promoção do clientelismo e da patronagem política, visando sobretudo a maximização de lucros em período eleitoral.

No continente africano, Resnick e Casale (2011) afirmam que os altos níveis de pobreza e desemprego conduzem os jovens a integrarem-se em partidos políticos, pensando com isso mudarem a sua sorte individual. Partidos políticos são percebidos como centros de emprego e espaços de possibilidades para uma ascensão social imediata. Neste processo, a distinçáo ideológica entre uma esquerda do povo e uma direita elitista como acontece nos países ocidentais é nula, visto que em África a distinção partidária faz-se entre o partido histórico e partido de oposição. Em Cabo Verde, de forma particular, entre o partido da independência ${ }^{4}$ (PAICV) e o partido da democracia (MPD).

Se no continente africano as reivindicações juvenis da geração realista e pragmática surgiram a partir da falência do projeto nacionalista de desenvolvimento manifestada na crise econômica e ajustamento ideológico (DIOUF, 2003), como provam os recentemente levantamentos juvenis em Moçambique, África do Sul, Senegal, Tunísia e Egito, protagonizadas pela geração denominada por Honwana (2012) de waithood, isto é, jovens que vivem em suspenso entre a adolescência e a idade adulta porque lhes faltam empregos que os conceda autonomia e liberdade, em Cabo Verde o projeto ideológico neoliberal fez emergir um mal-estar juvenil e urbano manifestado no novo tipo de violências de rua surgidas na primeira metade dos anos de 2000.

Para Roque e Cardoso (2012) os estudos sobre a violência têm ignorado a componente política, através da substituição artificial da noção violência política pela violência social, numa época em que reações às desigualdades e à marginalização têm estado na base de inúmeros motins urbanos a nível mundial. Concordamos que um dos desafios das Ciências Sociais é enfrentar "a progressiva despolitizaçáo e consequente deslegitimação e criminalização da violência” (ROQUE e CARDOSO, 2012, p. 295). Contudo, analisando a violência dos gangues de rua na Praia, consideramos que ela não pode ser percebida como uma expressão politizada dos motins que marcaram a paisagem urbana europeia e americana do século passado ou de alguns contextos africanos dos últimos anos.

Enquanto expoente máximo da violência pública dos últimos anos na capital cabo-verdiana a atuação desses grupos deve ser pensada como uma reação do mau

\footnotetext{
${ }^{4}$ Ou partido histórico.
} 
funcionamento das instituiçôes políticas, que tem um significado expresso na reivindicação social derivado da correspondência entre aquilo que é esperado e aquilo que é recebido (FISCHER apud RODRIGUES, 2010), faltando-lhe uma estratégia e um objetivo claro, que lhe poderia fornecer uma identidade de resistência (CASTELLS, 2003).

A partir da ideia defendida por Zizek (2009) de que encontramos numa era pós-ideológica, demonstrada no caso cabo-verdiano por Costa (2013), constatamos que no contexto em análise essa situação facilita a utilização político-partidária das associaçóes juvenis e dos gangues de rua, usadas como forma de legitimar uma determinada governança ou de manter um dado poder. Por outro lado, o forte envolvimento juvenil nas campanhas eleitorais de 2008, 2011 e 2012, não obstante o seu desinteresse político patenteado na sua fraca participação no recenseamento eleitoral anteriormente referenciada, deve ser refletido a partir da cultura de necessidade existente no país (LIMA, 2012).

As privações sociais e a segregação das oportunidades têm estruturado a cultura política dos cidadáos, colocando-os à mercê dos apetites vorazes dos partidos políticos, não escapando também a essa lógica alguns jovens acadêmicos que viram a sua liberdade intelectual capturada (OGACHI, 2011) pelas organizações partidárias, tendo em conta o "seu silêncio ensurdecedor perante alguns indícios de nepotismo, de partidarização da administração pública e de mercantilização do voto" (COSTA, 2013, p. 317). Situação já tornada pública em Cabo Verde, por um ex-membro do governo, que depois das eleiçôes presidenciais em 2011 acusa os dirigentes do seu partido de usarem a máquina governamental para vencer essas eleiçóes ${ }^{5}$, no entanto perdidas pelo candidato apoiado pela oposição.

$\mathrm{Na}$ análise da participação política juvenil cabo-verdiana, para além da relação desigual de poder entre estratégia e táctica (CERTEAU, 1994), sendo a primeira por nós entendida como um instrumento usado pelos partidos políticos visando a maximizaçáo do poder e a segunda como um instrumento utilizado pelos jovens ou grupos em situação de subalternidade visando a maximização do lucro, a noção de infrapolítica (SCOTT, 2013 [1992]) surge como uma ferramenta conceptual importante que proporciona uma leitura do discurso oculto destes sujeitos.

O rap, aqui entendido como uma táctica utilizada pelos jovens "periféricos" como forma de dialogarem com o poder, tem sido um importante veículo de

\footnotetext{
${ }^{5}$ As eleições presidenciais de 2011 tiveram três candidatos, sendo dois do PAICV, o que contribuiu para disputa dentro deste partido.
} 
formação política da juventude africana e tem contribuído para a proliferação da ideia de que os políticos africanos pouco espaço concedem aos seus jovens para uma real participação política (HONWANA, 2012). Sendo assim, o rap proporciona uma nova esfera de participação sociopolítica e de reivindicação de direitos. Por esta razão, a compra do apoio dos rappers com vista à divulgação da propaganda partidária ou institucional é hoje uma realidade em Cabo Verde, como forma a garantir que a mensagem chegue a uma maior audiência.

\section{Democracia e participação politica em Cabo Verde: o que nos diz a empiria?}

Chegado a este ponto, o objetivo consiste agora em avaliar o respaldo das instituições políticas democráticas nos contextos mapeados. Ou seja, o nosso esforço consiste em saber qual é a relação que os cidadáos cabo-verdianos mantêm com as suas instituições políticas a despeito do passado anteriormente descrito? Numa primeira fase apresentaremos o panorama das percepçóes da democracia e a participação política, no geral. De seguida, analisaremos de forma desagregada a participação da juventude em comparação com o cenário nacional.

Dados do Afrobarometer (2011), apresentados nos Gráficos 1 e 2, revelam que os cidadãos cabo-verdianos apoiam o sistema democrático do país, ou seja, têm uma atitude positiva face à sua democracia. O que significa que os aspectos teóricos do sinergismo entre instituições políticas (a que foram sujeitos) e culturais (que assimilaram), aos quais fizemos menção, vistos em linhas gerais se concatenam no sentido de uma afeição à democracia. 
Gráfico 1 - Atitudes face à democracia

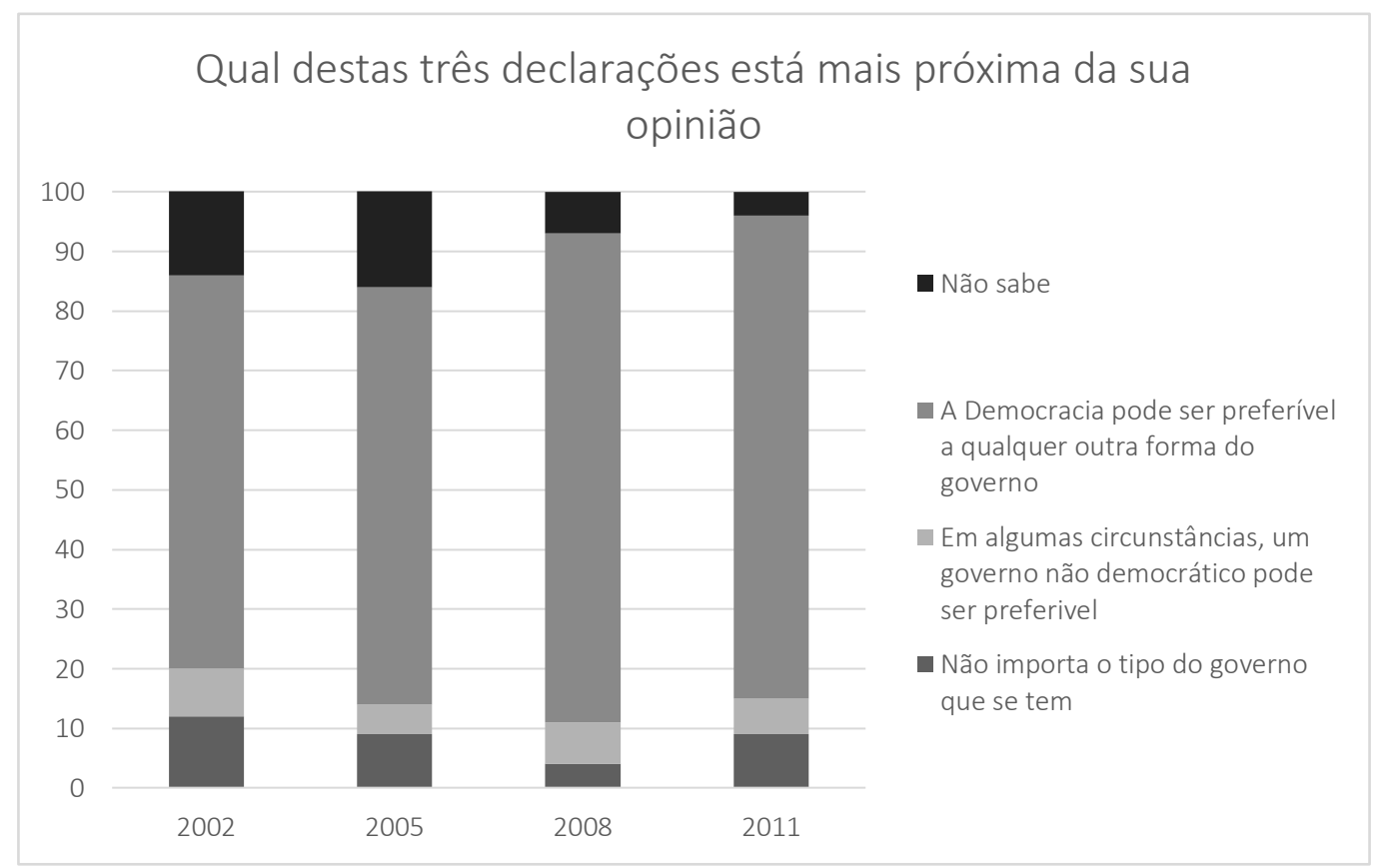

Fonte: Elaborado por Varela (2013) a partir de dados do Afrobarometer (2011).

Um dado a extrair do cruzamento entre a sustentação teoria e a empiria, capaz de avaliar a primeira dimensão de análise, é de que em Cabo Verde o passado marcado pela opressão e exclusão política (colonial mais nacional) ainda se encontra bem patente na mente dos cidadãos, pois estes preferem a democracia a qualquer forma do governo. 66\% em 2002, 70\% em 2005, 81\% em 2008 e a mesma percentagem em 2011. Ao examinar a ficha técnica desta sondagem, observa-se que $49 \%$ das pessoas que responderam às questóes tinham idades para além dos 35 anos (portanto gentes que lidaram com partes do colonialismo e o autoritarismo do partido-único) e 51\% tinham entre os 18 a 34 anos, partes de jovens que ainda receberam heranças do passado autoritário uma vez que a transição democrática só ocorreu em 1991. Nestes termos, a acreditar na tendência, escassa é a probabilidade do apoio e regresso a um sistema ditatorial. 
Gráfico 2 - Grau de democracia existente

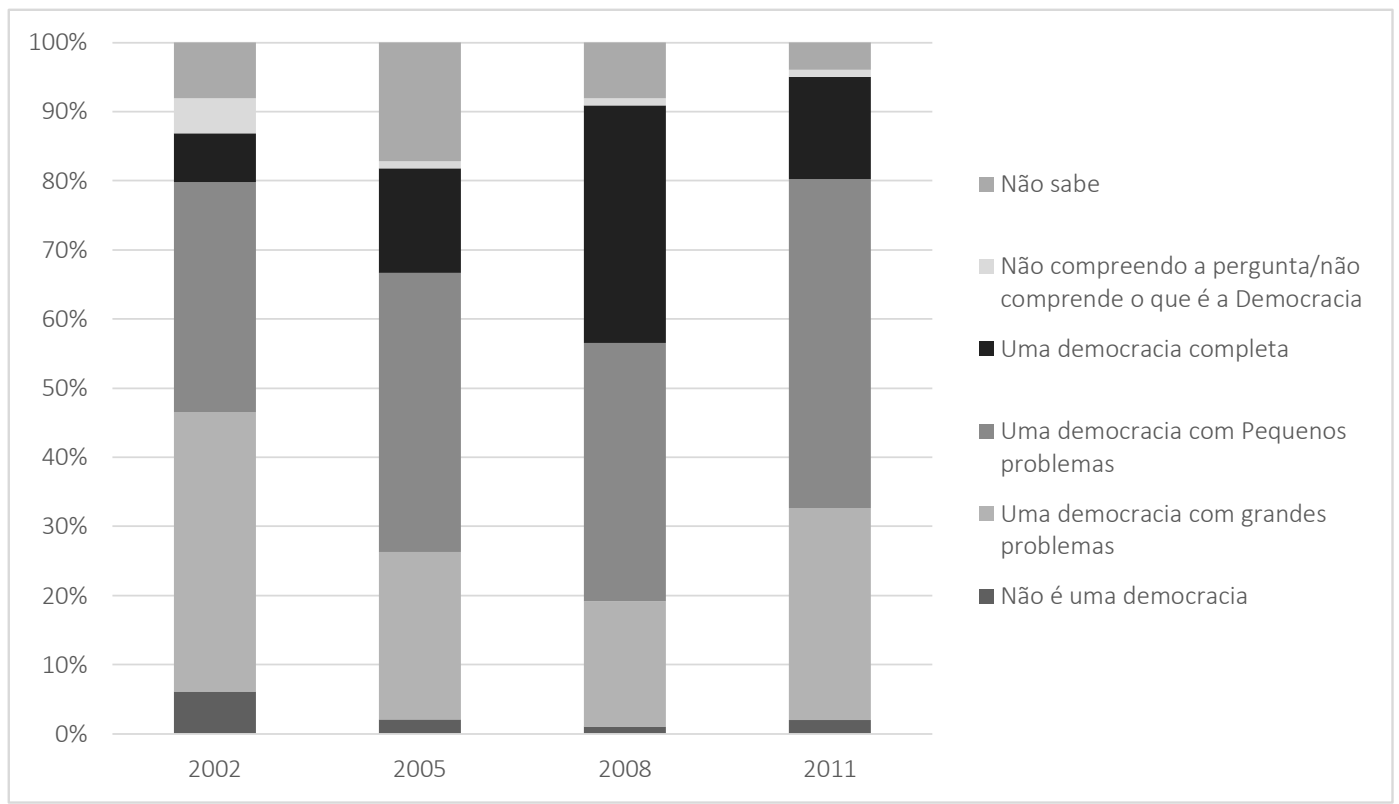

Fonte: Elaborado por Varela (2013) a partir de dados do Afrobarometer (2011).

Todavia, é possível notar também que questionados sobre o grau de democracia existente no país (Gráfico 2) numa sequência temporal de 2002 a 2011, os cidadãos demonstram melhorias nas suas respostas, apontando que se está perante uma democracia com pequenos problemas. No entanto, quando se cruza essa resposta com outras dadas em questôes mais detalhadas como, por exemplo, na avaliação do desempenho do governo numa escala de 10 (dez) itens (Gráfico 3), alguma incongruência sobressai.

Ora, num país onde o tecido empresarial é fraco e o maior empregador é o Estado, os cidadãos avaliam o governo de forma altamente negativa em matéria da criação de emprego - $69 \%$ consideram a performance muito rum, e simultaneamente uma larga percentagem responde que se vive numa democracia com poucos problemas. 
24 | Aquilino Varela e Redy Wilson Lima

Gráfico 3 - Performance do governo

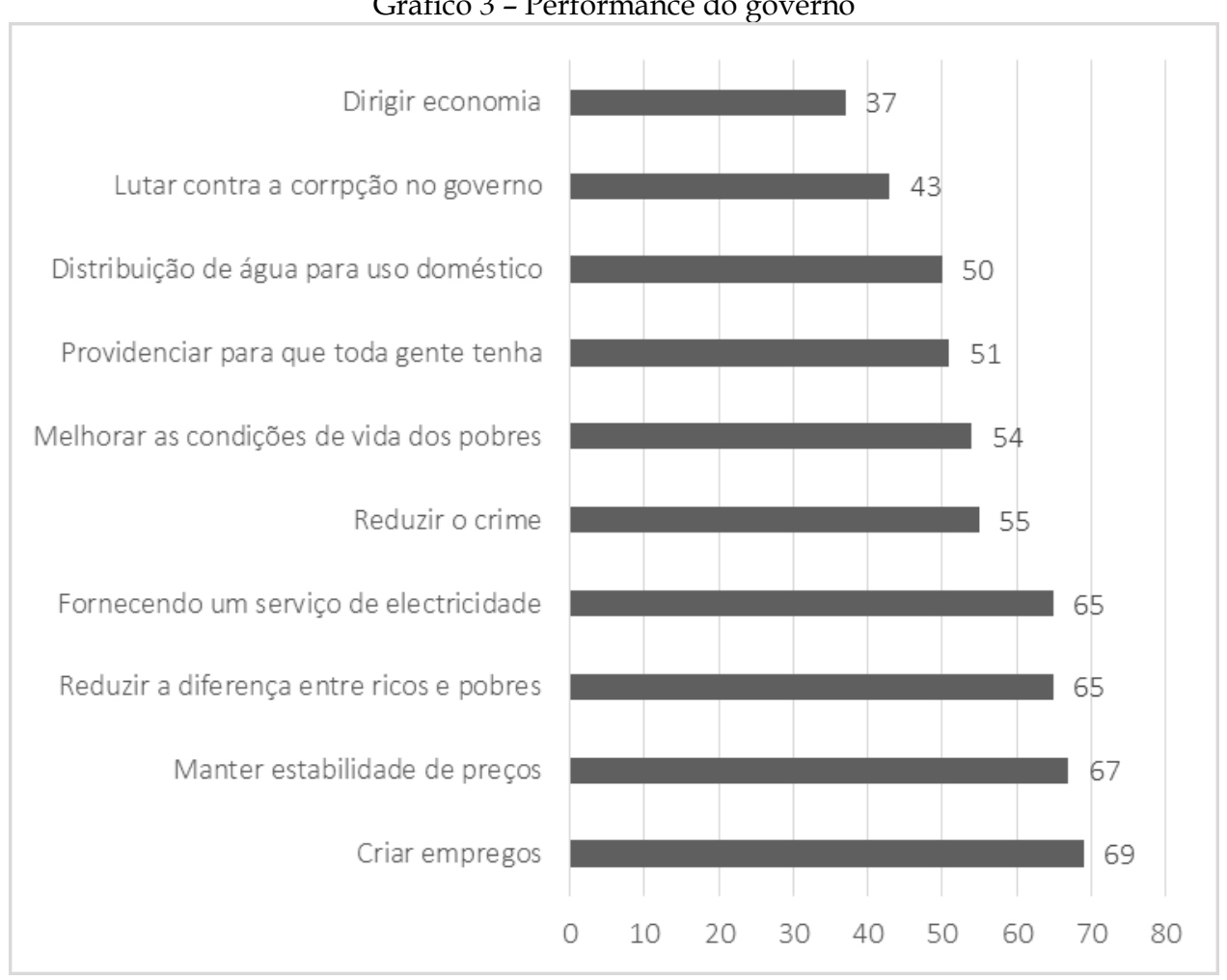

Fonte: Afrobarometer (2011).

Uma outra incongruência pode ainda ser notada em relação às respostas sobre o significado da Democracia (Gráfico 4) comparada com a performance do governo. Avalia-se mal o governo em matéria da criação do emprego, mas valoriza-se muito bem a democracia na sua componente de Liberdades civil e pessoal. 
Gráfico 4 - Significado da democracia

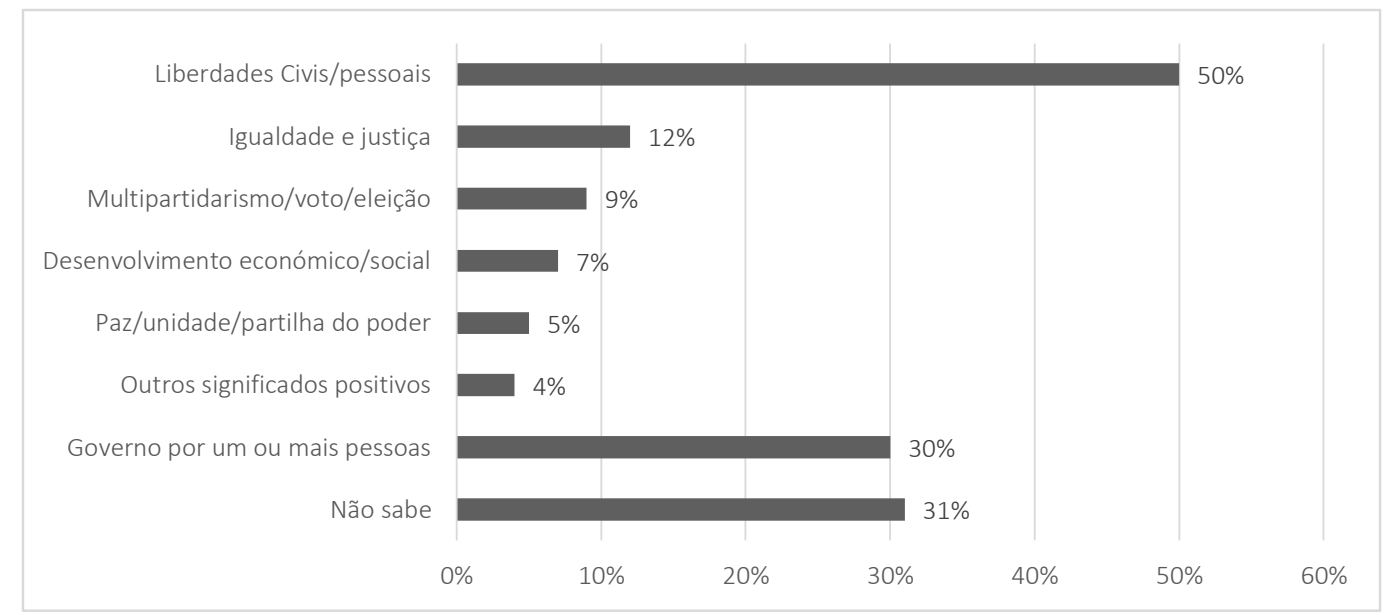

Fonte: Afrobarometer (2011).

Observando o Gráfico 5, cujos dados remetem-nos para a participação política nas últimas eleições, denota-se que há uma grande afluência dos cidadãos nas reuniōes das campanhas e nos comícios dos partidos políticos - 53\% afirmam ter participados em reunióes e comícios partidários. Os dados, de fato, não mentem. Todavia, ali reside um dos pontos nodais que este trabalho busca explorar. Em tempos de campanha política, como demonstraremos a seguir, com recurso às entrevistas semiestruturadas, cria-se uma rede de clientela para ostentar apoiadores e eleitores. Os jovens, sobretudo, são pagos pelos partidos políticos e/ou seus respectivos candidatos para irem de casa em casa contatarem os potenciais votantes levando a mensagem da entidade patronal que lhes paga a diária.

Gráfico 5 - Participação Política nas últimas eleições

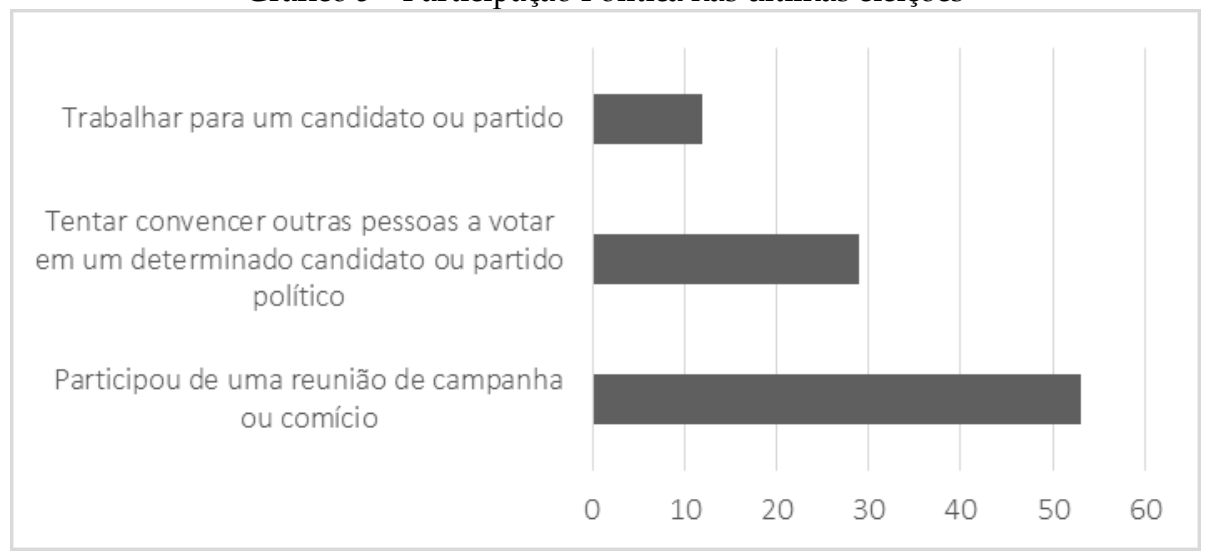

Fonte: Afrobarometer (2011). 
Não podendo estar os candidatos na mesma hora e em todos os locais, a representação se faz pela via do clientelismo juvenil, cuja taxa de desemprego foi de $27,1 \%$, em 2011, segundo os dados do INE o que no nosso entendimento propicia tal recrutamento.

Nestes termos, avaliar a participação política por aquela via é incorrer em aferições não verossímeis. $\mathrm{O}$ contributo da participação que dali emerge não constituem valias para, nos termos em que defende Ortiz (apud BAQUERO, 2009), que dão para possibilitar a melhoria nas condiçôes de tomada de decisão e de ações coletivas no grupo; não eleva a corresponsabilidade dos atores sociais envolvidos; não facilita os processos de aprendizagem social; não possibilita a emancipação cidadã e, nem tampouco, promove a articulação e o envolvimento dos grupos sociais e excluídos, nas tomadas de decisão.

\section{O contexto eleitoral cabo-verdiano e a relação manipuladora partidos politicos, gangues de rua e rappers}

No dia 27 de Fevereiro de 2008, três meses antes das eleições autárquicas, o jornal Expresso das Ilhas (EI) noticiou um tiroteio entre os gangues de rua de Paiol e Achada de Santo António na zona balnear de São Francisco ${ }^{6}$. No dia das eleiçóes legislativas, a seis de Fevereiro de 2011, a Televisão Nacional de Cabo Verde (TCV) abriu o noticiário da hora do almoço dando conta de ameaças e tiroteios nas imediaçóes do espaço onde se encontrava a urna, no Paiol, entre gangues de rua ligados ao PAICV e MPD. As acusaçóes foram mútuas.

Sobre o primeiro caso, ficou-se sabendo que o patrocinador do passeio tinha sido o então Presidente da CMP.

Quem patrocinou o passeio foi o X, quem me disse foi você mesmo, alegando que eu náo ia ser convidado porque sou do MPD. O X, no domingo, deu-lhes dinheiro para fazerem a festa e de seguida para o passeio. Inclusive, ele disse que não vai dar mais dinheiro para os jovens de Paiol porque fizeram feio em São Francisco [...] Falta muito pouco para as eleiçôes e muito são os que já começaram a fazer aldrabices com intimidaçôes para comprar votos e a consciência dos cidadãos, disse, indignado, um cidadão que deu voz ao Expresso das Ilhas, pedindo anonimato para revelar os lamentáveis acontecimentos que se vem registrando na zona do Paiol. Segundo a fonte, o dinheiro é dado sobretudo aos jovens desempregados, e grupos de thugs (EXPRESSO DAS ILHAS, 2008, p. 20).

\footnotetext{
${ }^{6}$ Localidade situada nos arredores da cidade da Praia.
} 
A relação na época eleitoral entre gangues de rua e partidos políticos na Praia tem sido alvo de conversas em vários espaços, havendo relatos da utilização sistemática desses jovens noutras regiōes do país. Nas eleições autárquicas de 2012, na ilha do Fogo, houve acusações mútuas dos partidos sobre a utilização de gangues da Praia e jovens deportados dos EUA como arma de intimidação político-partidária. Encontramos estas situaçóes nas narrativas do rap, como na música $N u$ Korda Soldadus .

O PAICV e o MPD dividiram o contingente/Nas campanhas eleitorais recebem-nos com o sorriso na cara/Findo a campanha somos considerados delinquentes/Deram dinheiro para comprar votos compramos makarov/O mesmo makavov que serve para assaltar nas ruas/Matou-se uma vez matou-se duas vezes mas ninguém foi culpabilizado/Matou-se pela terceira vez e ninguém foi culpabilizado de novo e nem nunca o culpado aparecerá/O problema não é deles assim como a ELECTRA $8 / S e$ matarmo-nos uns aos outros o problema é nosso/Irmão acorda e consciencializa-te/Somos todos irmãos, devemos acordar e enfrentar a vida (BATALHA e 4ARTK, 2012).

Estas narrativas permitem-nos captar as representações das populações em relação ao pleito eleitoral, uma vez que tanto em forma como em conteúdo "estão diretamente ligados, e se constituem através das múltiplas e sutis relações entre o contador de estória, o grupo e as preocupaçóes da comunidade" (JOVCHELOVITCH, 2000, p. 144). O rapper, posicionando-se como representante do povo, usa a sua música como forma de chamar a atenção para os efeitos colaterais dessa relação, que quando não calculados acabam por reproduzir uma cultura de violência nos agrupamentos juvenis que noutras conjunturas condenam.

$\mathrm{O}$ recurso aos gangues por parte dos atores políticos é um fenômeno recorrentemente usado em outras paragens. Gambetta (1996) expóe o negócio de proteção que a máfia siciliana impóe aos políticos, e Dickie (2007) fala em abordagem homeopática da ordem pública para designar o processo pelo qual os políticos buscam amizades com grupos criminosos, utilizando-os como caçadores de votos e agentes não-oficiais da polícia. No Quênia, nas eleiçóes presidenciais de 2002, Daniel Arap Moi utilizou o gangue Mungiki, que integra jovens residentes dos bairros pobres da capital que intimidam e obrigam os eleitores a votarem no

\footnotetext{
${ }^{7}$ Acordem soldados.

${ }^{8}$ Empresa responsável pela distribuição da energia eléctrica e água. Alusão à profunda crise energética que se verificou na cidade capital até 2013.
} 
candidato que tinha escolhido para ser o seu sucessor (KAGWANJA apud RESNICK e CASALE, 2011).

Cabo Verde, apesar de possuir um estatuto de democracia modelo em África, deparou-se com esta realidade nas últimas eleições, com maior intensidade em 2011, ano em que houve maior número de homicídios $\left(28^{9}\right)$ relacionados com a atividade de gangues de rua na Praia (LIMA, 2014). No período eleitoral analisado, registrouse um total de 238 homicídios no país (UNODC, 2014), e sabendo que uma parte do dinheiro amealhado por estes grupos é direcionado para o aumento do seu arsenal bélico, explorar a relaçáo entre o contexto eleitoral e a intensidade de conflitos armados na Praia torna-se forçoso.

Évora e Ramos falam de mercantilismo do voto, referindo-se aos assédios dos partidos políticos aos cidadãos no período eleitoral. Dos 1.261 pesquisados num estudo sobre a participaçáo eleitoral dos cabo-verdianos elaborados pelas autoras, $11 \%$ dos inquiridos declararam terem sido aliciados, sendo que na faixa etária de 24 a 34 anos, $14 \%$ afirmaram já ter sido aliciado com dinheiro ou bens materiais para votar. No EI José Alvarenga (ÉVORA e RAMOS, 2013), num estudo realizado na cidade da Praia referente às eleições legislativas de 2011, afirma que 6\% dos inquiridos, num universo de 1.250 eleitores com idade superior a 18 anos, disse ter recebido dinheiro para votar numa determinada lista.

Falar da participação política organizacional é referir-se àquilo que Braga da Cruz (1985) chama de grupos ou organizações parapolíticos, isto é, grupos que não tendo objetivos exclusivos ou prioritariamente políticos, nem sempre atuando em terreno político, têm sobre os processos políticos (neste caso, eleitoral), uma influência importante.

Numa sociedade em que a juventude se encontra despolitizada e que 57,6\% dos inquiridos situados na faixa etária dos 18 e 24 anos não se encontravam recenseados em 2010, por mero desinteresse político (ÉVORA e RAMOS, 2013) e, dos que estavam, nessa faixa etária apresentavam um maior número de abstenção, os jovens, desideologizados, tornam-se num potencial cliente do mercado informal do voto em Cabo Verde onde grupos parapolíticos juvenis são facilmente transformados em proletários dos partidos políticos.

\footnotetext{
${ }^{9}$ Número de membros de gangues de rua assassinados na Praia. Dados de Lima (2014). Houve 74 homicídios no país nesse ano (UNODC, 2014). Os dados da Polícia Nacional (PN) apontam para 53 homicídios e a discrepância com os dados da UNODC reside no facto de que este último engloba tanto os dados da PN como da Polícia Judiciária.
} 
Tendo em conta que existiam 104 gangues de rua em 2011 na Praia (LIMA, 2014) e mil e quatro associações juvenis (a maioria informais) no país em $2013^{10}$, dos quais 92 estariam registrados na Câmara Municipal da Praia em 2010 ${ }^{11}$, um exército parapolítico poderia ser facilmente construído pelos partidos políticos com capacidade financeira para (des)mobilização eleitoral.

Em relação às gangues de rua, aproveitando a relação ambígua existente entre eles e a população dos territórios que dominam, uma vez que, se por um lado, estes, sentem-se amedrontados e culpam os jovens por trazerem a violência ao bairro, por outro, é com o background desses jovens advenientes dos seus affairs que os apoios comunitários são por ali canalizados, sobretudo à nível da assistência social, e reconhecendo o poder comunitário dos mesmos torna-se evidente o recurso a eles em época eleitoral, tendo a vitória como o único resultado esperado.

Em todas as eleiçóes os jovens participam. Vejo jovens participarem pregando cartazes, no ativismo, na comissão de zonas representando os partidos... e também vejo os jovens considerados thugs ${ }^{12}$ participarem nas campanhas. Procura-se a todos porque o que interessa na política é apenas vitória $\left(\mathrm{KULA}^{13}, 2013\right)$.

Se a mercantilização do voto é um assunto de que se fala desde os anos de 1990, o fenômeno de "mercenarismo" juvenil via envolvimento de gangues de rua na "batalha" eleitoral, não sendo novo, ganha novas proporções a partir de 2011. Os jovens, porque em estado de vulnerabilidade, são vítimas da máquina política. Como defendera Merton a propósito das funçóes da máquina política nos EUA, "as classes desfavorecidas constituem um subgrupo a quem a máquina política satisfaz as necessidades não adequadamente satisfeitas pela estrutura social legítima" (MERTON, 1957, p. 199).

Évora e Ramos (2013) mostram que os jovens têm pouco interesse em seguir informaçôes políticas, dado entendido pelas autoras como um indicador da dificuldade encontrada pelos partidos políticos em mobilizar potenciais votantes. Assim, o recurso às gangues para caça aos votos surge como uma estratégia partidária para contornar essa situação, uma vez que são poucas as pessoas que declararam ter uma participação ativa nas atividades partidárias. Os jovens, segundo os dados

\footnotetext{
${ }^{10}$ Dados da Federação Cabo-verdiana da Juventude (2013).

${ }^{11}$ Dados da Direção da Juventude da Câmara Municipal da Praia (2010).

${ }^{12}$ Forma como normalmente os jovens associados a gangues de rua são designados em Cabo Verde.

13 Os entrevistados são líderes e membros de alguns gangues de rua da Praia cujos nomes foram substituídos por nomes fictícios de forma a proteger as suas identidades.
} 
apresentados, tendem a participar mais ativamente em grupos desportivos, religiosos ou juvenis, sobretudo os do sexo masculino, o que a nosso ver faz com que uma boa parte dos gastos partidários sejam canalizados para a compra de equipamentos desportivos, patrocínio de passeios para fora da cidade e festas de grupos juvenis.

As falas dos líderes e membros de gangues específicos fornecem insights para compreender a emergência de alguns padróes de interação entre o sistema político e o sistema parapolítico na Praia.

P: Qual o tipo de acção fazem para os políticos?

R: Somos os seus guarda-costas e intimidamos os seus adversários. Numa batalha tens de ter a tua tropa.

P: Mas sei que já apoiaste os dois partidos...

R: Já estive dos dois lados porque eu não sou tropa de ninguém, de nenhum deles. Eu sou tropa do meu money, do bem-estar da minha família. O que não nos dáo durante cinco anos tomamos durante a campanha. Só que não sou burro.

P: Quanto dinheiro ganhaste nestas últimas campanhas?

R: Não tenho noção. Pego-o e arrebento-o num instante.

P: Quanto conseguiste amealhar em um dia?

R: Cento e cinquenta mil escudos ${ }^{14}$, numa missão.

P: Dividiste com os rapazes?

R: Claro... já houve épocas que ganhei oitenta mil escudos ${ }^{15}$ sozinho. Para haver dinheiro suficiente para dividir com os rapazes fazemos outras coisas, tipo bater nos adversários por vinte ${ }^{16}$, cinquenta mil escudos ${ }^{17}$ cada um [...].

P: Mas um brotha disse-me que a única coisa que vos dizem para não fazer é matar...

R: Dizem porque pode trazer problemas para eles... podes não aguentar a pressáo depois e disseres que foi fulano quem te mandou. Mas nós já estivemos perto de matar alguém. Na última eleição (autárquicas de 2012) ou matávamos ou éramos mortos. Sabes que as coisas estavam quentes.

P: E sobre manifestaçáo que fizeram contra inauguraçáo da placa?

R: É lógico que foi trabalho pago. Nenhum thug dá cara gratuita. Missão era para que o evento náo se realizasse, mas realizou porque estávamos dos dois lados... isto é business.

P: Mas se já sabem que costumas estar com um, como é que depois confiam em ti?

R: Porque tenho bons argumentos. Sei como pegá-los... (GOLI, 2013).

\footnotetext{
${ }^{14}$ Cerca de 4,095,61 reais.

${ }^{15}$ Cerca de $2.184,33$ reais.

${ }^{16}$ Cerca de 546,081 reais.

${ }^{17}$ Cerca de 1.365,20 reais.
} 
Roessler (2005), analisando as novas guerras africanas, fala de violência estatal privatizada para dar conta de um subconjunto de violência estatal, coerção orquestrada pelo Estado contra uma real ou potencial oponente feito por atores não estatais, como os vigilantes, paramilitares e milícias, que direta ou indiretamente são apoiados pelo governo, através do fornecimento de armas, logística e inteligência, financiamento ou permissão de atividades repressivas dos grupos informais por ganhos políticos. Não queremos, com a mobilização desse autor, afirmar que em Cabo Verde vivemos uma realidade assim dimensionada. No entanto, o trabalho de campo revela que os partidos políticos organizam grupos parapolíticos juvenis (gangues de rua, rappers ou associaçooes comunitárias) com vista a ganhar vantagem na arena eleitoral.

Até tenho vontade que haja campanha a toda hora, todos os meses. Quando ganhem ou percam, não querem saber da sociedade. Até o número de telefone que nos dão para chamá-los desativam... não entendo. O sistema político é lixado. É apenas interesse. Como já o conhecemos por trabalhar com eles, sabemos isso mas fingimos acreditar e vestimos a camisola do partido.

P: E são leais?

R: Nós não somos leais a nenhum partido. É quem nos procurar, MPD, PAICV... interessa-nos aquilo que nos possa beneficiar, assim como eles. Tratam-nos como bandidos. Tomam dinheiro e colocam cartazes, tomam dinheiro e retiram a bandeira (do adversário), façam segurança e não deixem ninguém votar, arranjem pessoas para votar em nós. Não nos prometem nem trabalho nem formação. Fazemos um trabalho não sem antes negociar o preço. Temos automóveis à nossa disposição e protecção da polícia. Teve um dia que a minha malta estava a retirar a bandeira do adversário aqui na zona, apareceu uma unidade de piquete que disse-lhes para continuarem mas sem dar nas vistas. Se não estivéssemos em campanha apanhavam logo. Desde quando a polícia é nosso amigo? (KULA, 2013).

O que se nota é que essa relação é, por um lado, de mútua instrumentalização e, por outro, conseguida através de um contrato laboral previamente negociado. $\mathrm{O}$ estudo de Évora e Ramos (2013) aponta o fato de que a maioria dos jovens desinteressados na política ser estudante com níveis de formação média ou superior e desempregado ${ }^{18}$. Numa sociedade em que a taxa de alfabetização juvenil é extremamente elevada $(96,9 \%$ na faixa etária 15 a 24 anos) e 5,1\% da população total

18 21,3\% dos desempregados possuem o ensino secundário completo e 15,6\% uma formação superior (INE, 2014). 
possui uma formação superior (INE, 2010), o desinteresse político poderá querer significar uma "insatisfação com a forma como o sistema está a funcionar, o descontentamento com o desempenho dos políticos e das instituiçóes" (ÉVORA e RAMOS, 2013, p. 95). É de realçar que os jovens da faixa etária de 18 a 34 anos são apontados por estas autoras como sendo os mais críticos em relação aos aspectos ligados à governança e ao desempenho dos atores políticos.

Ontem saiu daqui um carro cheio de jovens. Sabe-se que existe forças de segurança em Cabo Verde, mas são os meus irmãos que colocam a trabalhar como seus seguranças. Levas armas de fogo, faca... vender a vida por mil e quinhentos escudos ${ }^{19}$. [...] Já que o governo tem seus seguranças oficiais para os proteger, não deve ser os thugs quem têm de lhes prestar apoio, sabendo que nos criticam fora da época de campanha (PRETA, 2011).

A população juvenil cabo-verdiana é fortemente marcada pela pobreza e desemprego. Os dados da pobreza nos mostram que 49\% dos pobres têm menos de 15 anos (DECRP, 2004) e dos 16,4\% desempregados em idade ativa no ano de 2013, 22,8\% residiam na Praia. Agregando a faixa etária de 15 a 24 anos com a de 25 a 34 anos, constatamos que existem 54,3\% de desempregados jovens no país (INE, 2014). A taxa do subemprego situa-se em $37,8 \%$, o que somando a dificuldade no acesso às oportunidades laborais (MARTINS, 2013) abre possibilidades ao recrutamento partidário dos jovens durante as eleiçóes.

Comparando os dados do desemprego na Praia nos anos de 2012 e 2013, que aumentou 5,6\%, e relacionando-o com o material de campo faz nos supor que o contexto eleitoral poderá criar oportunidades laborais sazonais aos jovens. Contudo, os jovens mostram-se pouco confiantes no sistema político em geral e nos políticos em particular, recebendo as promessas feitas com cepticismo. Évora e Ramos (2013) revelam que a maioria dos inquiridos afirma não acreditar nas promessas políticas e $60 \%$ declarou não acreditar que os políticos colocassem os interesses do povo acima dos interesses partidários.

Sabes como é que se enriquece nesta terra? Candidatas-te a PrimeiroMinistro ou Presidente da Câmara. Repara que quando saem compram mansóes e têm terrenos por todos os lados... e é apenas entre eles, entre familiares. Nós continuamos na pobreza. O povo paga imposto todos os dias, ouves que Cabo Verde recebeu ajuda e não vemos nada (TXIKAYA, 2013).

${ }^{19}$ Cerca de 41.4979 reais. 
Para além de não confiarem nos políticos, os nossos entrevistados concebem a sua relação com os partidos políticos como meramente mercantilista, colocando-se na posição de proletários e através da táctica ludibriam o poder com discursos ocultos que funcionam como uma potente crítica às práticas partidárias.

O rap constitui uma dessas táticas que busca criar um espaço social alternativo de participação, conforme pode ser observado no excerto abaixo, da música $N u K r e^{20}$.

\begin{abstract}
Queremos que Cristina Duarte ${ }^{21}$ nos explique dos cinquenta mil contos que saiu do cofre do Estado para distribuição junto das associações partidárias ${ }^{22} /$ Queremos a justiça a balançar igual a uma balança bem regulada/Lancha a voar enquanto boeing velho se encontra no chão/Traficantes livres enquanto os nossos jovens na prisão/Desocupados enquanto no nosso bolso metem a mão/A verdade é que ser político é ser ladrão [...]/Precisamos ser um pouco mais violentos/Se o governo é corrupto vamos tirar-lhes para fora do parlamento (BATALHA, Ty ALC e FARP, 2012).
\end{abstract}

No Senegal o rap é entendido como um ator político capaz de derrubar um regime político. No ano de 2000, rappers senegaleses apoiaram o candidato presidencial vencedor Abdoulaye Wade e este conseguiu uma massiva mobilização dos jovens às urnas (APPERT, 2011). Mais tarde, em 2012, desiludidos com Wade, derrubá-lo tornou-se a força motriz dos rappers, que recanalizaram o apoio para Macky Sall (LEBRAVE, 2012), vencedor das eleiçôes.

Em Cabo Verde, apesar de também o rap ter abraçado a luta contra a corrupção, exploração, neocolonialismo, a cleptocracia e da miséria social, no plano do ativismo político, a nosso ver, fruto da despolitização e institucionalização juvenil acima referida, náo conseguiu criar um espaço político autônomo, tornando-se um alvo fácil da cooptação partidária e institucional.

Todavia, o rap enquanto espaço de resignificação da mediação política pode estar a denunciar a falência de esferas tradicionais de mediação política, como partidos políticos. A afinidade eletiva entre o mercado eleitoral e o recrutamento de gangues entre jovens desempregados deve ser tomado como urgente preocupaçáo. Pois essa afinidade eletiva que se consubstancia em práticas parapolíticas pode repercutir na autoridade das instituiçóes políticas (Estado). Tilly (1985) defende a

\footnotetext{
${ }^{20}$ Nós queremos.

${ }^{21}$ Ministra das Finanças de Cabo Verde.

${ }^{22}$ Nas vésperas do dia do voto nas eleiçóes legislativas de 2011.
} 
esse respeito que entre Estado e crime organizado há somente uma distinção de escala. Qualquer organização criminosa representa um novo governo em potencial.

Aquilino José Manuel Lopes Varela foi professor na Universidade de Santiago e no Instituto Superior de Ciências Jurídicas e Sociais de Cabo Verde. É doutorando da PEC-PG em Ciência Politica na Universidade Federal de Rio Grande do Sul e bolsista da CAPES. E-mail: varelaaquilino@hotmail.co

Redy Wilson Lima é investigador colaborador do CESA/ISEGULisboa, professor assistente convidado no Instituto Superior de Ciências Jurídicas e Sociais de Cabo Verde e doutorando em Estudos Urbanos na FCSH-UNL/ISCTE-IUL. E-mail: redywilson@hotmail.com

\section{Referências}

AFROBAROMETER. A Qualidade da Democracia e da Governação em Cabo Verde. 2011. Disponível em: <http://www.afrobarometer.org/files/documents/media_briefing/cve_r5_ presentation 1.pdt>. Acessado em:

ALMOND, Gabriel; VERBA. Sidney. The Civic Culture: Political Attitudes and Democracy in five nations. Thousand Oaks: Sage Publications, 1963.

APPERT, Catherine. Rappin' griots: producing the local in Senegalese Hip-Hop. In: SAUCIER, Paul

K. (Ed.). Natives tongues: an african hip-hop reader. Trenton: African Word Press, 2011. p. 3-21.

ARENDT, Hannah. Origens do Totalitarismo. $3^{a}$ Reimpressão. Tradução de Roberto Raposo. São

Paulo: Companhia das Letras, 1998.

BAQUERO, Marcello. Alcances e limites do capital social na construção democrática. In:

BAQUERO, Marcello. Reinventando a Sociedade na América Latina: Cultura Política, Gênero,

Exclusão e Capital Social. Porto Alegre: UFRGS, 2001. p.19-49.

BAQUERO, Rute. Jovens e a participação sociopolítica - em que paradigma de participação suas açóes se inserem? In: BAQUERO, Rute (Org.). Agenda Jovem: o Jovem na agenda. Ijui: Ed. Unijui, 2009.

BATALHA, Hélio; 4ARTK. Nu Korda Soldadus. In: Golpe Di Stadu I1. 2012.

BATALHA, Hélio; Ty ALC; FARP. Nu Krê. In: Golpe Di Stadu II. 2012.

BRAGA DA CRUZ, Manuel. A participação política da juventude em Portugal. Análise Social, Lisboa, vol. XXI, n. 3, p. 1067-1088, 1985.

CABRAL, Amílcar. Unidade e luta, a arma da teoria. Volume 1. Obras escolhidas. Praia: Fundação Amílcar Cabral, 2013. 
CARDOSO, Humberto. O partido único em Cabo Verde: um assalto à esperança. Praia: Edição do Autor, 1993.

CARVALHO, José Murilo de. Cidadania no Brasil: o longo caminho. Rio de Janeiro: Civilização Brasileira, 2002.

CASTELLS, Manuel. A era da informaçâo: economia, sociedade e cultura: o poder da identidade. Volume II. Lisboa: Fundação Calouste Gulbenkian, 2003.

CERTEAU, Michel de. A invenção do quotidiano. 16º Edição. Petrópolis: Vozes, 1994.

COSTA, Suzano. Sociedade civil, Estado e qualidade da democracia em Cabo Verde: entre a letargia cívica e a omnipresença do leviatã. In: SARMENTO, Cristina M.; COSTA, Suzano (Orgs.). Entre África e a Europa: nação, Estado e democracia em Cabo Verde. Coimbra: Almedina, 2013. p. 273329.

DAHL, Robert. Poliarchy: participation and opposition. New Haven: The Yale University Press, 1971.

DECRP. Documento de estratégia de crescimento e de redução de pobreza. Praia: MFP, 2004.

DICKIE, John. Cosa Nostra: História da máfia siciliana. Lisboa: Edições 70, 2007.

DIOUF, Mamadou. Engaging postcolonial cultures: african youth and public space. African Studies Review, vol. 46, n. 2, p. 1-12, 2003.

DIREÇÃO DA JUVENTUDE. Lista de associações e grupos informais. Praia: CMP, 2010.

DOWNS, Anthony. Uma teoria económica da democracia. São Paulo: USP, 1999.

ÉVORA, Roselma; RAMOS, Noemi. Estudo sobre a participação eleitoral em Cabo Verde: uma perspectiva de género - Relatório Final. Praia: PNUD/UNICEF/UNFRA, 2013.

EXPRESSO DAS ILHAS. Três pessoas atingidas com arma de fogo: jovens são intimidados com dinheiro e promessas. Expresso das Ithas, n. 325, p. 20, 2008.

FEDERAÇÃO CABO-VERDIANA DA JUVENTUDE. Mapeamento nacional das organizaçóes juvenis. Praia: MJ, 2013.

FREEDOM HOUSE. Democratic breakthrougs in the balance. Washington; New York: Freedom House, 2013.

GAMBETTA, Diego. The sicilian mafia: the business of private protection. Cambridge: Harvard University Press, 1996.

GONZÁLES, Rodrigo; CASTRO, Henrique. Democracia participativa, desarrollo y capital social. Santiago: Revista Política, 2008.

HONWANA, Alcinda. The time of youth: work, social change, and politics in Africa. Sterling: Kumarian Press, 2012.

HUNTINGTON, Samuel. The Third Wave: Democratization in the late Twentieth Century. Oklahoma: University of Oklahoma Press, 1991.

INE. Apresentação dos resultados definitivos do recenseamento geral da população e habitação. Praia: INE, 2010.

. Inquérito multi-objectivo contínuo - Estatísticas do emprego e mercado de trabalho: Apresentação dos principais resultados. Praia: INE, 2014.

INGLEHART, Ronald; WELZEL, Christian. Modernização, mudança cultural e democracia. São Paulo: Verbena, 2009.

JOVCHELOVITCH, Sandra. Representações sociais e esfera pública: a construção simbólica dos espaços públicos no Brasil. Petrópolis: Vozes, 2000. 
KINZO, Maria D’Alva G. Os partidos no eleitorado: Percepçóes públicas e laços partidários no Brasil. Revista Brasileira de Ciências Sociais, v. 20, n. 57, p. 65-81, 2005.

LAMOUNIER, Bolívar. Forma de governo e representação: Três estudos. São Paulo: Idesp, 1987.

LAMOUNIER, Bolivar. Partidos e Utopias: O Brasil no limiar dos anos 90. Sáo Paulo: Loyola, 1990.

LEBRAVE, Benjamin. Enough is enough: the rap revolution of Senegal. Dundee: Clash Magazine, 2012. Disponível em: <http://www.clashmusic.com/features/enough-is-enough-the-raprevolution-of-senegal>. Acesso em: 06 mar. 2014.

LIMA, Redy W. Rappers cabo-verdianos e participação política juvenil. Revista Tomo, São Cristóvão, no 21, p. 263-294, jul./dez. 2012.

. The written press and the coverage of conflicts between gangs in Cape Verde. In: BUSSOTI, Luca; BARROS, Miguel de; GRÄTZ, Tilo. (Eds.), E-book Media freedom and right to information in Africa. Lisboa: ISCTE-IUL, 2014.

LOPES, José V. Aristides Pereira: Minha vida, nossa história. Praia: Spleen Editora, 2012.

MAINWARING, Scott; SCULLY, Timothy. The Institutionalization of Party System in Latin America. In: MAINWARING, Scott; SCULLY, Timothy (Orgs.). Building Democratic Institutions: Party System in Latin America. California, Stanford University Press: 1995.

MARTINS, Filipe. Entre projecto e convivência: Ser jovem nas periferias pobres do Mindelo, Cabo Verde. 2013. 394 f. Tese (Doutorado em Antropologia) - ISCTE-IUL, Lisboa, 2013.

MARSHALL, Thomas H. Cidadania, Classe Social e Status. Rio de Janeiro: Zahar, 1967.

McCLOSKY, Herbert. Political Participation. In: SILLS, David L. (Ed.). International Encyclopedia of the Social Sciences. New York: Macmillan and Free Press, 1968. p. 252-265.

MERTON, Robert. Social Theory and Social Strucure. Glencoe: Free Press, 1957.

MILLS, C. Wright. A elite do poder. Tradução de Waltensir Dutra. Rio de Janeiro: Zahar, 1962.

MOISÉS, José Â. (Org.). Democracia e Confiança: Por que os Cidadãos Desconfiam das Instituições democráticas? $1^{a}$ ed. São Paulo: Editora da Universidade de São Paulo, 2010.

MUXEL, Anne. Jovens dos anos noventa: à procura de uma política sem "rótulos". Tradução de Inês Rosa Bueno. Revista Brasileira de Educação, n. 5, p. 151-166, mai./ago. 1997.

NOVO JORNAL DE CABO VERDE. Manifestação estudantil: Terça-feira negra para a Praia. Novo Jornal de Cabo Verde, n. 126, p. 11-14, 1994.

OGACHI, Ibrahim O. Neo-liberalism and the subversion of academic freedom from within: money, corporate cultures and 'captured' intellectuals in African Public Universities. JHEA/RESA, vol. 9, n. 1-2, p. 25-47, 2011.

PANEBIANCO, Ângelo. Modelos de Partido: Organização e poder nos Partidos Políticos. São Paulo: Martins Fontes, 2005.

PATEMAN, Carole. Participação e Teoria Democrática. Rio de Janeiro: Paz e Terra, 1992.

PUTNAM, Robert D. Comunidade e Democracia: A experiência da Itália Moderna. Rio de Janeiro: FGV Editora, 1996.

QUERIDO, Jorge. Um Demorado Olhar sobre Cabo Verde: o País, sua Génese, seu Percurso suas Certezas e Ambiguidades. Lisboa: Chiado, 2011.

RESNICK, Danielle; CASALE, Daniela. The political participation of Africa's youth: turnout, partisanship and protest. Afrobarometer, 2011. Disponível em: <http://www.afrobarometer.org/files/documents/working_papers/AfropaperNo136.pdf>. Acesso em: 31 de mar. 2014. 
ROESSLER, Philip. Donor-induced democratization and the privatization of state violence in Kenya and Rwanda. Comparative Politics, vol. 37, n. 2, p. 207-227, jan. 2005.

RODRIGUES, Daniel M. Violências urbanas em França: excepção ou novíssima guerra? Univ. Rel. Int., vol.8, no 2, pp. 95-120, 2010.

ROQUE, Sílvia; CARDOSO, Katia. Conclusóes. Dos atores às trajectórias: desafios de uma análise centrada na 'modernidade' das violências. In: PUREZA, José M.; ROQUE, Sílvia; CARDOSO, Katia (Orgs.). Jovens e trajectórias de violências: Os casos de Bissau e da Praia. Coimbra: Almedina/CES, 2012. p. 293-297.

SANCHES, Edalina R. Institucionalização do Sistema Partidário e Democratização em Cabo Verde (1991-2011). In: SARMENTO, Cristina M.; COSTA, Suzano (Orgs.). Entre África e a Europa: Nação, Estado e democracia em Cabo Verde. Coimbra: Almedina, 2013. p. 249-270.

SCOTT, James. A dominação e a arte da resistência: discursos ocultos. Lisboa: Letra Livre, 2013 [1992].

TILLY, Charles. War making and state making as organized crime. In: EVANS, Peter B.; RUESCHEMEYER, Dietrich; SKOCPOL, Theda (Orgs.). Bringing the State back in. Cambridge: University Press, 1985. p. 169-191.

UNODC. Global study on homicide 2013: trends, contexts, data. Viena: UNODC, 2014.

VARELA, Aquilino. A relação partido-eleitor em Cabo Verde: uma análise através da volatilidade eleitoral [no prelo], 2014a.

VARELA, Odair Bartolomeu. Cabo Verde: A máquina burocrática estatal da modernidade (16141990). In: SARMENTO, Cristina Montalvão; COSTA, Suzano (Orgs.). Entre África e a Europa: Nação, Estado e democracia em Cabo Verde. Coimbra: Almedina, 2013b. p. 173-208.

WEBER, Max. Ciência e Política: duas Vocaçôes. Tradução de Leonidasv Hegenberg e Octany Silveira da Mota. São Paulo: Cultrix, 2004.

ZIZEK, Slavoj. Violência: seis notas à margem. Lisboa: Relógio D’Água Editoras, 2009.

Texto recebido em 15 de abril 2014. Aprovado em 04 de maio de 2014. 

